\title{
JOURNAL.RU
}

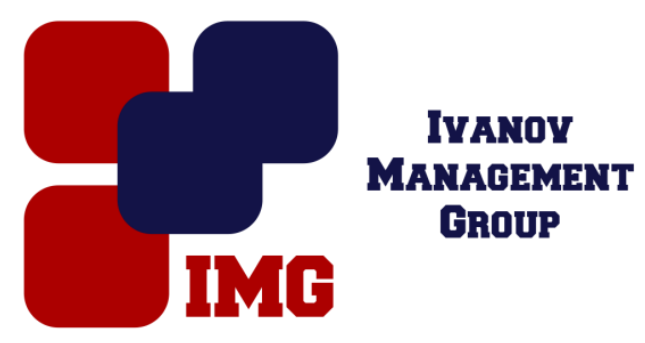

Ткачева Л.О., Гудима Л.В.

Санкт-Петербургский Государственный университет Санкт-Петербург, Россия

doi: $10.18411 / \mathrm{lj}-31-07-2017-10$

idsp 000001:1j-31-07-2017-10

\section{Изменение параметров ЭЭГ в процессе созерцания Тибетских мандал}

\begin{abstract}
Аннотация
Исследование посвящено изучению изменения функционального состояния мозга в процессе созерцания Тибетских мандал взрослыми испытуемыми ( $\mathrm{N}=21)$. Испытуемым предъявлялись Тибетские мандалы и, идентичные им по уровню информационной сложности и спектральным характеристикам, контрольные изображения. На основе расчета фрактальной размерности ЭЭГ была обнаружена тенденция к стабилизации и более низким значениям величины фрактальной размерности ЭЭГ в процессе просмотра мандал.

Ключевые слова: мандала, фрактальная размерность ЭЭГ,
\end{abstract} функциональное состояние.

Мандала это санскритское слово, обозначающее круг или округлый объект. Этот круг имеет особые качества, выраженные в комбинации идей периферии и центра - борьба противоположностей заключена в самой геометрии мандалы. Вечный аспект круга, который не имеет ни начала, ни конца, соединен с квадратичными формами. В Буддийском искусстве мандалы используются как основной инструмент медитации. Считается, что в процессе созерцания, они пробуждают ощущение сакрального переживания в личном опыте [1]. Мандалы используются в арт-терапиикак психотерапевтический прием и психодиагностический инструмент [2]. Предполагается, что созерцание внешнего и внутреннего круга мандалы способствует запуску процессов 
рефлексии [3]; может успешно использоваться среди техник помощи выхода из пост-травматического стрессового расстройства [4].

Мы предположили, что процесс созерцания мандал должен сопровождаться специфическим паттерном изменения биоэлектрической активности мозга, отличным от созерцания аналогичных цветных картинок без эзотерической смысловой нагрузки. Для проверки гипотезы мы провели психофизиологический эксперимент $(\mathrm{N}=21)$ с регистрацией ЭЭГ (19 монополярных отведений по схеме 10:20). В качестве стимульного материала испытуемым последовательно предъявлялись 3 типа традиционных Тибетских мандал и 3 типа контрольных изображений, соответствующих мандалам по информационной сложности и спектральным характеристикам. ЭЭГ фиксировалась непрерывно.

Для определения соотношения различных ритмических составляющих ЭЭГ был произведен спектральный анализ с преобразованием Фурье (в частотном диапазоне от 0,53 до 70 Гц, с режекторным фильтром 45-55 Гц). Был произведен расчет фрактальной размерности ЭЭГ, как меры информационной сложности в работе мозга в текущий момент времени[5], методом Хигучи.

Статистически значимых различий в спектральном диапазоне и мощности спектра ЭЭГ в процессе созерцания мандал и контрольных изображений получено не было. По результатам вычисления фрактальной размерности (ФР) ЭЭГ была обнаружена статистически значимая тенденция: при просмотре мандал ФР ЭЭГ сохраняется на относительно невысоком уровне и значимо не изменяется, в то время как при просмотре фоновых картинок ФР ЭЭГ динамически изменяется, значительно увеличиваясь к концу просмотра (Рис.1). Статистически достоверные отличия по изменению величины ФР ЭЭГ получены во фронтальных и центральных отведениях левого и правого полушарий: F7, F8, F3, F4, FZ, C3, C4. 


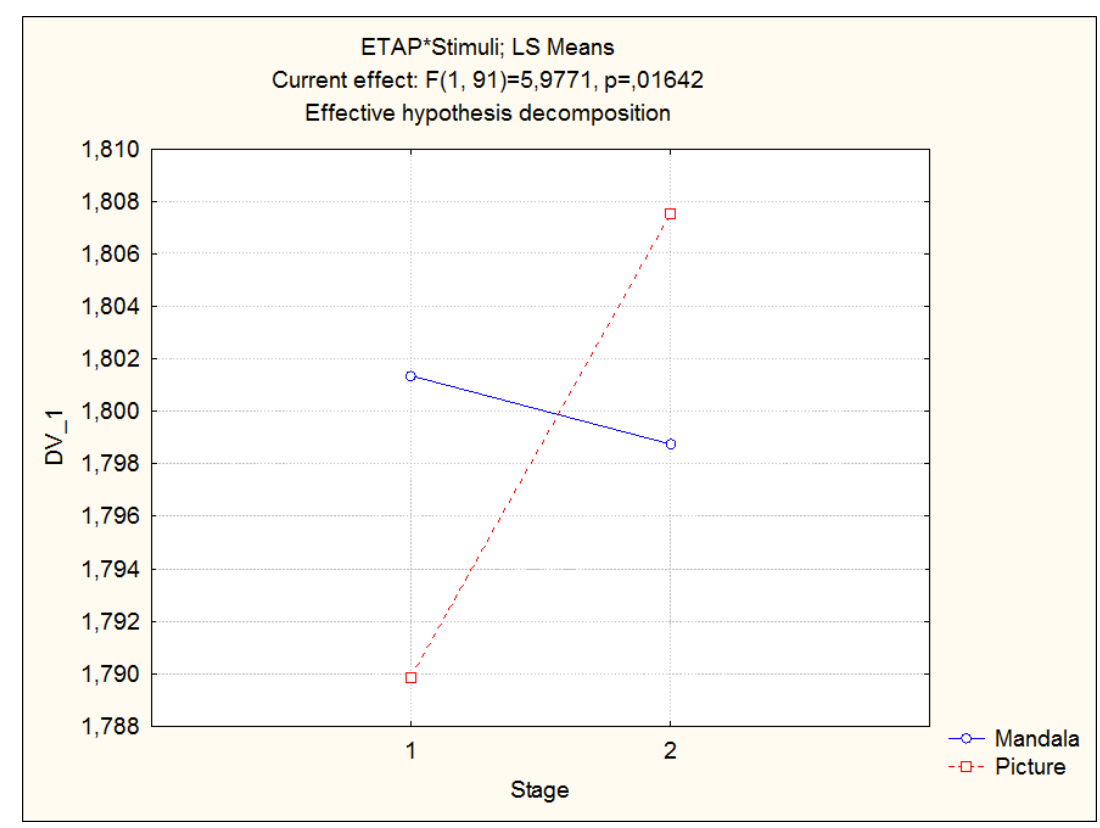

Рис. 1. Изменения величины ФР ЭЭГ в прочессе просмотра мандал и контрольных изображений

Полученные результаты иллюстрируют, что во время просмотра мандал сохраняется более стабильное упорядоченное состояние мозга, характеризующееся информационной простотой и отражающееся в невысоких значениях ФР ЭЭГ, что может соответствовать состоянию релаксации. В процессе просмотра фоновых картинок мозг находится в относительно более дестабилизированном, сложном состоянии, возможно, характеризующимся поиском и генерацией идей, что отражается в повышении величины ФР ЭЭГ. Известно, что чем больше величина ФР, тем сложнее система, поэтому данную величину можно рассматривать как меру стохастичности изучаемого процесса [6]. Было показано, что в состоянии покоя у здоровых людей регистрируются относительно низкие показатели размерности ЭЭГ [7]. Было обнаружено фокусированное снижение величины ФР ЭЭГ в передних и центральных отведениях в состоянии медитации [8]. В работе посвященной изучению восприятия смысла визуально предъявляемых текстов наименьшие значения ФР ЭЭГ сигнала были получены в момент осознания, характеризующегося предельной простотой в работе мозга - когда все сведено к единственной альтернативе и лишняя информация отброшена[9].

Результаты исследования подтверждают потенциал мандал оказывать гармонизирующее влияние на функциональное состояние человека, однако нейрокогнитивный механизм воздействия мандал остается вопросом открытым, требующим дальнейших исследований. 
1. BaderC. Mandalaand Faces//Encyclopediaof Psychologyand Religion. 2014. P. 1064-1066.

2. Диагностика в арт-терапии. Метод «Мандала». Под ред. Копытина А.И. СПб: Речь, 2005. C. 27-35.

3. Lee W. BaileyMandala//EncyclopediaofPsychologyandReligion. 2014. P. 1058-1064.

4. Brillantes-Evangelista G. Visual Artsand Poetry Usagefor PTSD: ConsiderationsforTreatment//ComprehensiveGuidetoPost-TraumaticStressDisorders. 2016. P. 1935-1955.

5. Lutzenberger W., Birbaumer N., Elbert T. et al. Dimensional analysis of the human EEG and intelligence//Neurosci. Lett. 1992. V. 143. P. 10.

6. Меклер А.А., Болотова Е.В. Возрастные изменения нелинейных динамических характеристик ЭЭГ //Матер.междунар. конф. “Психология XXI века"/Под ред. Чеснокова В.Б. СПб.: СПбГУ, 2005. С. 124.

7. Shen Y., Olbrich E., Achermann P., Meier P.F. DimensionalcomplexityandspectralpropertiesofthehumansleepEEG // Clin. Neurophysiol. 2003. V. 114. P. 199.

8. Голошейкин С.А. Психофизиологический анализ особенностей эмоциональной реактивности у лиц, практикующих медитацию. Автореферат на соискание ученой степени к.б.н., Новосибирск, Типография СО РАМН, 2003.

9. Tkacheva L.O., Gorbunov I.A., Nasledov A.D. Reorganization of system brain activity while understanding visually presented texts with the increasing completeness of information//Human Physiology, 2015, vol. 41, №1, p. 11-21. 